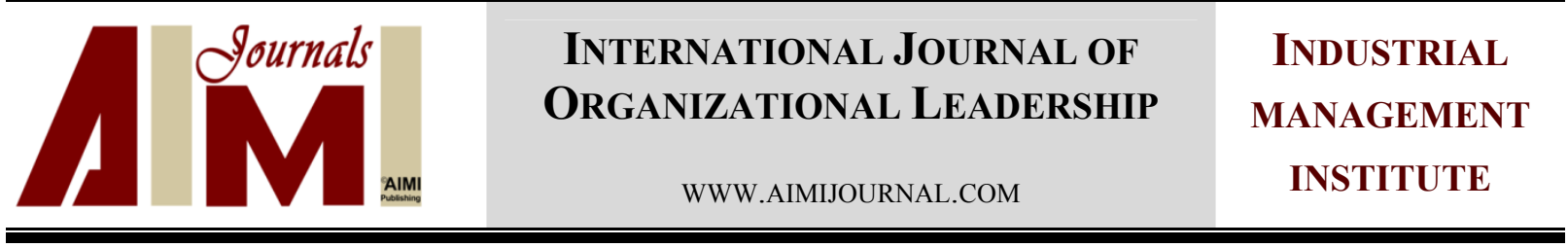

\title{
A comparative study of the impact of emotional, cultural, and ethical intelligence of managers on improving bank performance
}

\author{
Shahram Mirzaei Daryani ${ }^{1 *}$, Samad Aali ${ }^{2}$, Amir Amini $^{3}$, Bahman Shareghi ${ }^{4}$ \\ ${ }^{1}$ Department of Management, Ardabil Branch, Islamic Azad University, Ardabil, Iran \\ ${ }^{2}$ Department of Management, Tabriz Branch, Islamic Azad University, Tabriz, Iran \\ ${ }^{3} \mathrm{MSc}$. Graduate of Industrial Engineering, Alghadir Institute of Higher Education, Tabriz, Iran \\ ${ }^{4}$ Young Researcher and Elite Club, Ardabil Branch, Islamic Azad University, Ardabil, Iran
}

\section{Keywords:}

Emotional Intelligence,

Cultural Intelligence,

Ethical Intelligence,

Banks' Performance

\section{Received}

09 May 2016

Received in revised form

01 August 2016

Accepted

18 August 2016

Correspondence:

shahram.daryani@yahoo.com

\section{Abstract}

\begin{abstract}
Many factors influence human and social systems' behaviour.The main aim of the current study was to check the status of intelligence in emotional, cultural, and ethical dimensions. Besides, the study examined the effect of those dimensions of intelligence on improving the performance of public and private banks in Ardabil. The current study was practical in terms of the method; cross-sectional in terms of time; inductive in terms of implementation logic; quantitative in terms of the implementation process; and causal in terms of purpose. The population of the study included the managers of public banks of Melli and Sepah and private banks of Pasargad, Eghtesad-e Novin, and Mehr of Ardabil. A questionnaire was set up by the researcher to evaluate the effects of intelligence in emotional, cultural, and ethical dimensions on the banks' performance. The Cronbach test was used to test the reliability of the questionnaire. Descriptive statistics such as frequency, medium, and mean were used to describe the demographic of the participants. Inferential statistic tests such as KolmogorovSmirnov, regression, and independent $t$ were used to analyse the data. The findings of the study showed that in both public and private banks, intelligence in emotional, cultural, and ethical dimensions had a positive impact on the performance of the banks. The effects of cultural intelligence on the performance of the public banks were more than the private banks. However, the impact of emotional and ethical intelligence on the performance of the private banks was more than the public banks.
\end{abstract}




\section{Introduction}

Today, affected by the competitive market, many organisations are subject to change more than ever before. These changes require certain characteristics and skills of the managers and their employees as well as close collaboration among them. Emotional intelligence (EI or EQ), cultural intelligence (CI or CQ), and ethical intelligence are considered as the basic factors for effective communication between the managers and their employees. Comprehensive studies have been carried out from the mid-nineteenth up to present to identify the effective elements in the success of the managers. Some of the characteristics of a successful manager are the ability to lead, adoption to the needs of the environment, handling the tasks and the employees, motivating the employees, and focusing on human resources' development. Considering the importance of this issue and focusing on human resources as the main capitals of the organisations, scholars are seeking for mechanisms to assist the managers with the solutions that improve the organisations status. The growing influence of the humanities, sociology, political science, ethnography, and psychology in the respective fields have brought impressive impact on the evolution of human's systems such as the organisations. In other words, they played a major role in the mental transformation of turning organization-based human to the human-based organisation. The position of these key principles has been a sustainable and effective change in the human's behaviour, personality, attitude, perception, and particularly learning. This phenomenon provides the required information for the managers and helps them to improve organisations. A manager can create necessary coordination between various departments and staff in line with the organization's goals. Besides, he/she gains selfmanagement ability. The current study aims to investigate the effects of the three dimensions of intelligence on the success of the managers in the case study. However, it is also important to note that human behaviour is influenced by a set of factors; therefore, investigating the impact of a unique factor on a phenomenon will not be free of defects.

\section{The Literature Review}

Today's world takes a fast complex trend. In this context, new management theories, designs, styles, and methods help organisations to put them on the path of sustainable growth and dynamism. The main key for the managers in managing the organisational changes is social interaction and appropriate manner.

Consequently, intelligence in emotional, cultural and ethical dimensions has effective factors in achieving that goal. It appears that managers can benefit from particular types of intelligence, namely emotional, cultural, and ethical to play a more effective role in the organisations. Intelligence is not a newly defined concept. Scholars suggested different definitions for it. One of the earliest definitions is proposed by Gardner (2002). In his words, intelligence refers to the human's brain ability to process the information and to solve the problems. From a different perspective, Crowne (2009) introduced the concept of social intelligence which refers to the ability someone has; so he can build good interaction with other people and do the interpersonal task.

Another type of intelligence is emotional intelligence. Scholars define emotional intelligence as someone's ability to manage emotions that include perceiving, expressing, 
understanding, and using emotion; so it can lead to effective performance (Crowne, 2009). Lastly, one of the new emerging concepts of intelligence refers cultural intelligence that is known as someone's power and capability to adapt and function efficiently in new cultural context (Early \& Ang, 2003).

Having different types of intelligence result in self-knowledge, self-confidence, understanding the environment, understanding others, healthy atmosphere, strengthening organisational health, comprehensive development of human resources, optimisation of interrelationships, and eventually would lead to synergism.

\section{Emotional intelligence}

In today's globalised world, individuals need to develop cultural intelligence to adapt more effectively to a new cultural setting where people think and behave differently (Kim,Yamaguchi, kim, \& Miyahara, 2015; Ward, Wilson, \& Fisher, 2011). Emotional intelligence has been defined as "a constellation of emotional self-perceptions" and "a collection of personality traits concerning people's perceptions of their emotional abilities" (Petrides, 2011). Goleman (1998) defines emotional intelligence as the ability to know, motivate, and manage self and others. He has divided the different dimensions of emotional intelligence into two main groups. First group refers to individual competencies or capabilities which include self-awareness, self-management and self-motivation components. Second group alludes to social competencies or capabilities which emphasise social consciousness and the power of organising a person's relationships such as empathy.

Four-dimensional model of emotional intelligence indicates that emotional intelligence is achieved from interrelated capabilities, namely understanding self and others' emotions, using emotions to facilitate decision making, perceiving the emotions, and regulating self and others' emotions.

People with high intelligence quotient (IQ) levels may progress in the world of science, but in personal and social life or in relationships with others they cannot treat effectively (Cobb \& Mayer, 2000). Therefore, because of the relevance of emotional intelligence and social and personal lives skills, it has a leading role in the success of individuals. Salovey and Mayer (1990) have used the term "emotional intelligence" as a form of social intelligence that involves the ability to control self and others' emotions and use this information as a guide for thought and action.

\section{Cultural Intelligence}

UNESCO declaration (1995) on the role of culture in the age of globalisation is in terms of involvement, acceptance and understanding of cultural diversity, differences and values, and respecting the rich diversity of cultures. CQ is conceptualised as a type of intelligence which reflects an individual's ability to deal adequately with people with various cultural backgrounds (Earley \& Ang, 2003). Cultural intelligence is a kind of intelligence that has a very strong correlation with the diverse working environment. The ability to adjust the values, traditions, and customs are different from what someone used to have in their cultural context and working in a different cultural environment represents the cultural intelligence. Van Dyne, 
Ang, \& Koh (2008) suggested that cultural intelligence is an intelligence supplement that can cope with describing variability and diversity in new cultural working conditions.

The CQ concept is progressed and detailed in next studies (Ang et al., 2007; Ang, Van Dyne, \& Tan, 2012; Van Dyne \& Ang, 2006). CQ is seen as an ability that permits human beings to comprehend and behave properly across a wide range of cultures. The authors have developed CQ as a multidimensional concept targeted at situations involving cross-cultural interactions arising from differences in race, ethnicity, and nationality (Ang et al., 2007). CQ comprises four distinct but linked components including metacognitive, cognitive, motivational, and behavioural intelligence. They believe that these components structure an individual's ability to learn about other cultures, the ability to learn about how to learn about culture, the desire to interact across cultures, and the ability to modify behaviour to act so successfully. Earley and Mosakowski (2004) have presented two major types of cultural intelligence, namely organizational cultural intelligence for organisations and cultural, ethnic, and geographic intelligence to understand country's culture.

Cultural intelligence is individual ability to understand, interpret, and act effectively in situations that have cultural diversity (Peterson, 2004).Cultural intelligence consists of three components such as the cognitive dimension, the physical dimension, and the emotional and motivational dimension (Earley \& Mosakowski, 2004). Earley and Ang (2003) state that cultural intelligence has four components, namely metacognitive component of cultural intelligence, behavioural component of cultural intelligence, motivational component of cultural intelligence, and cognitive component of cultural intelligence.

\section{Ethical Intelligence}

Ethics is defined as a set of principles that have often been applied as a prism for guidance and supervision (Arasteh \&Jahed, 2012). According to Barba (2001) Ethical intelligence is the ability to distinguish between right and wrong based on defined universal principles. In the modern world, this type of intelligencecan acts as a directing tool for measures. Also, ethical intelligence indicates the willingness and ability to set the standards above and beyond one's own interestsand issues such as effectiveness in the centre of individual reactions (Beheshtifar, Esmaeli, Nekoie, \& Moghadam, 2011). From the view of Borba (2001), the principles of ethical intelligence are sympathy(identifying feelings and interests of people), consciousness (knowing the correct way and acting in the same way), self-control (controlling and regulating one's thoughts and actions to stand against any pressure from inside and outside and to act in the way we feel that is right), care and respect (respecting others by polite and considerate behaviour), kindness (considering others' needs and feelings), patience(respecting the dignity and rights of all people, even those who disagree with our beliefs and behaviour), and fairness (rational choices and acting in a fair manner).

\section{Similarities and Differences between Emotional, Cultural, and Ethical Intelligence}

The main similarity of these dimensions of intelligence is in the field of human learning. In other words, the base is self and environmental knowledge. Therefore, in flexibility and adaptability of human beings, these aspects of human intelligence have a fundamental role. If 
the role of these intelligence dimensions is examined from a different perspective, the impact on interpersonal and cross-personal skills is apparent.

Aside from independent identity, these intelligence dimensions can impact on other areas of research that are debatable topics for a human. However, the focus of each of these dimensions of intelligence on certain characteristics that are close to each other in some way shows their different aspects. Emotional intelligence deals with consciousness, self-control, selfmotivation, empathy, and social skills. Following this, cultural intelligence focuses on understanding the norms, values and beliefs and ethical intelligence considers compliance with frameworks, standards, and discipline.

Marks, Horrocks, and Schutte's (2016) outcomes support a model that insecure attachment is connected with deficits in emotional intelligence, which in turn shows connection with imperfect health results. They investigate various mechanisms through which the two sorts of insecure attachment may influence on health.

In a study titled "Measuring and self-assessment of emotional intelligence characteristic in a sample of managers in Great Britain", the general characteristic of emotional intelligence of managers was shown significantly more than ordinary people, and female managers' emotional intelligence was more than males'. Also, female managers developed symptoms of biased evaluation in a specific form (Siegling, Sfeir, \& Smyth, 2014).

Brancu, Munteanua, and Golet (2016) used the CQ concept as systematic and effective analysis framework for studying the extent to which business students hold the essential intercultural intelligence to face future intercultural cooperation. Li, Mobley, and Kelly (2016) stated that personality and cultural intelligence would profit from an interactive approach, and that evaluation, collection, and progress of international talents should examine personality traits not in isolation, but in concert. The results of a research in Japan showed that motivated cultural intelligence can explain the difference in the interaction, differentiation, and function in accordance with the 5-factor model of personality (Huff et al., 2013).

According to O'donohue and Wickham (2010), understanding that how the ethical intelligence of employees of an organisation can be combined with induced institutional ethical principles is considered as a key factor for the organisation in achieving integration of its business goals together with its social responsibility. From their point of view, the salient features of high ethically intelligent employees and organisations include the followings:

Table 1

The Key Attributes of Ethical Intelligence

\begin{tabular}{ll}
\hline Key Attributes of Ethically Intelligent Employees & Key Attributes of Ethically Intelligent Organisations \\
\hline Social Intelligence & Ethically Infused Organisational Infrastructure. \\
Emotional Intelligence & $\begin{array}{l}\text { HRM Focused on Attracting, Developing, and Retaining Ethically Intelligent } \\
\text { 'Employees of Choice'. }\end{array}$ \\
Cognitive Intelligence & $\begin{array}{l}\text { Ethical Climate that Positively Shapes and Reinforces Ethical Managerial and } \\
\text { Employee Behaviour }\end{array}$ \\
\hline Ethical Maturity & \\
\hline
\end{tabular}


In his study, Rahimi (2011) examined the relationship between ethical intelligence and effectiveness of the organisations. He concluded that ethical intelligence has an undeniable impact on the progress of the organisation.

\section{Research Conceptual Model}

Reviewing the definitions and characteristics of the aforementioned dimensions of intelligence would lead to a better understanding of the effects of those dimensions of intelligence on individuals' performance and more specifically on the organisations. Self-awareness, selfcontrol, self- motivation, empathy and capability to communicate effectively with other people, self- confidence, conscientiousness, commitment, initiative, optimism, and service-orientation have been proposed as the basic characteristics of emotional intelligence. Besides, other features such as the individual adaptability to the customs and traditions of other people in the living and working environment, respecting the norms and values, trying to understand and use the language of other nations, respecting others' feelings and observing others' tastes and behaviors, and consciousness for cultural intelligence indicate the effects of those dimensions on the performance of individuals at any social positions. Furthermore, honesty, good mood, promoting spirituality and compliance with the frameworks and commitment to observe them for ethical intelligence are examples of the effects of the above-mentioned dimensions of intelligence. The conceptual model of the present study is depicted in Figure 1.

Emotional Intelligence

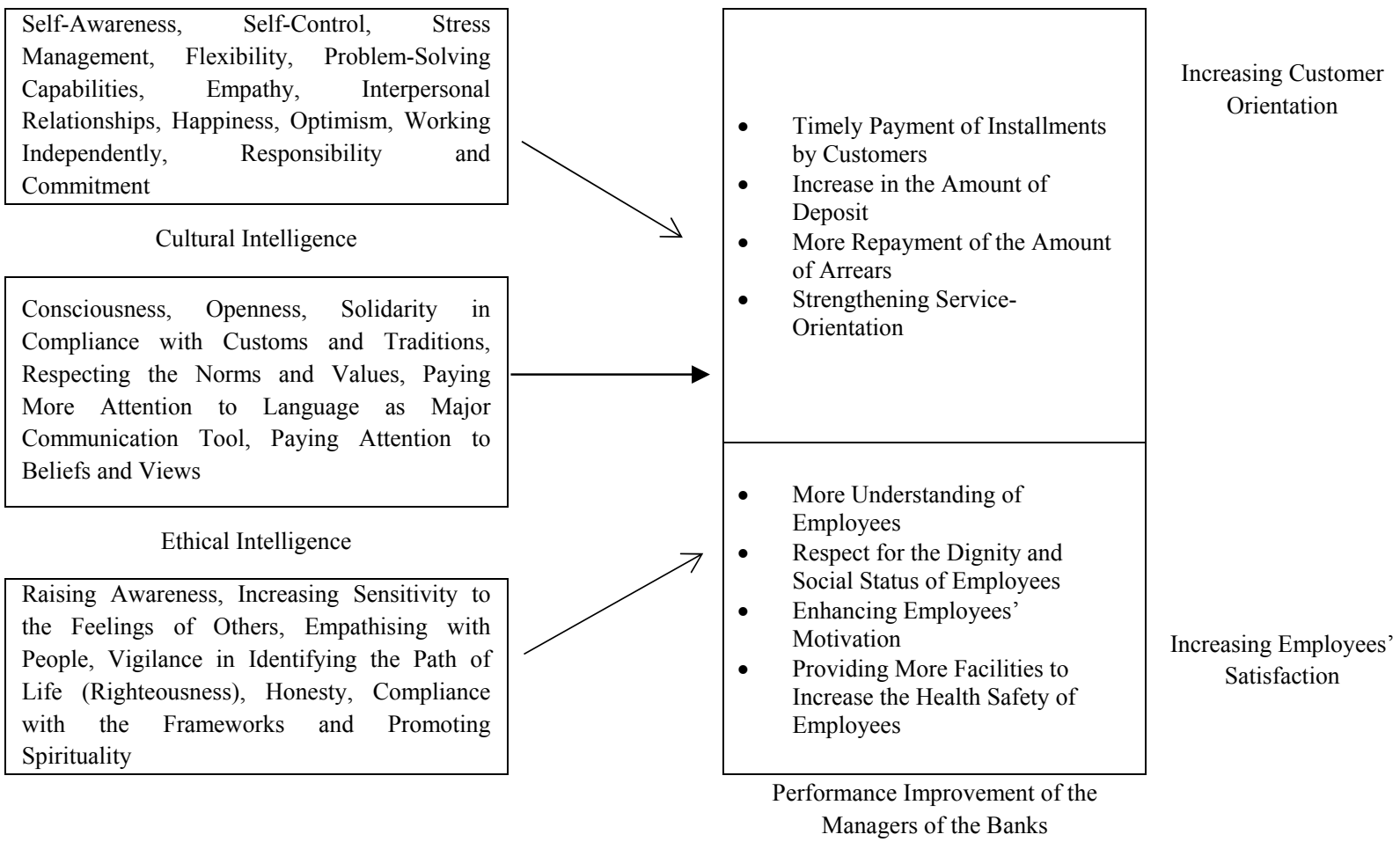

Figure 1.The research conceptual model 
It should be noted that this study aimed to independently investigate the effect of these dimensions of intelligence on improving the performance of the banks. Following this, the degree of their impacts has been measured in comparison with each other.

\section{Research Hypotheses}

The following research hypotheses guided the study:

$\mathbf{H}_{1}$ : The emotional intelligence of the banks' managers has a positive effect in improving the performance of the banks.

$\mathbf{H}_{2}$ : The cultural intelligence of the banks' managers has a positive effect in improving the performance of the banks.

$\mathbf{H}_{3}$ : The ethical intelligence of the banks' managers has a positive effect in improving the performance of the banks.

$\mathbf{H}_{4}$ : The intelligence in emotional, cultural, and ethical dimensions has positive impact on the managers' performance of the public and private banks of Ardabil.

H5: The degrees of the importance of the influence of intelligence in emotional, cultural, and ethical dimensions on the performance of the public and private banks are significant and different from each other.

$\mathbf{H}_{6}$ : The intelligence in emotional, cultural, and ethical dimensions has the significance difference on the managers' performance of the public and private banks of Ardabil.

\section{Method}

The present study is applied research in terms of the results, cross-sectional in terms of the implementation time, deductive in terms of the implementation logic, quantitative in terms of the implementation process, and causal with survey studies in terms of the purpose. The main aim of the study was to assess the status of intelligence in emotional, cultural, and ethical dimensions. Besides, the effects of the managers' intelligence in emotional, cultural, and ethical dimensions on the performance of the public and private banks in Ardabil are also evaluated.

The statistical population of the study included the managers of public and private banks of Ardabil. Meli and Sepah banks were selected among the public banks and Pasargad, Eghtesade Novin, and Mehr banks were chosen among the private banks. Random sampling was not required as the managers of all the branches of the selected banks were considered as the sample size.

Data was collected through a survey study. Besides, two sets of questionnaire were used for data gathering. First, a standard questionnaire of emotional intelligence, cultural intelligence and ethical intelligence and second, a questionnaire designed by the author of the current study to assess the performance improvement of the managers of the banks.

The three variables of this study namely emotional, cultural, and ethical dimension of intelligence were assessed through the use of 3 questionnaires which distributed among the managers of the public and private banks of Ardabil. The items have been set in the relevant questionnaires for more accurate measurement of each dimension of intelligence.

Haynes and Marans' (1999) standard questionnaire covers all the components of Goleman's (1998) emotional intelligence theory including personal capabilities of self- 
awareness, self-control, and motivation and social competencies of empathy and social skills. For example, the items like "You easily accept your disabilities and deficiencies" and "For an effective interaction control you pay enough attention to the feelings of the other side" are used in Emotional Intelligence questionnaire.

Standard questionnaire of cultural intelligence developed by the Early and Ang (2003) examines the components of cultural intelligence, namely metacognitive, cognitive, motivational and behavioural. Also the two following items including "When I interact with people of different culture, I am aware of their cultural knowledge" and "I enjoy living in unfamiliar cultures" are referred to the cultural dimension of intelligence.

Borba's (2005) standard questionnaire analyses seven principles of ethical intelligence, namely sympathy, consciousness, self-control, care and respect, kindness, patience and tolerance, and fairness through the options. Finally, the items including "My colleagues know me as a man of integrity" and "I care for the developmental and progress needs of my colleagues" have been used for the ethical dimension of intelligence.

Face validity of the questionnaire was approved by ten management professors. To test the reliability, split- half method was used. The test result was 0.71 for emotional intelligence, 0.71 for cultural intelligence, and 0.93 for ethical intelligence. To test the hypotheses and the generalizability of the results of the statistical population, Kolmogorov-Smirnov test, regression, independent t-test, and chi-square test were used. Besides, a set of analyses has been conducted on this basis.

\section{Results}

Descriptive statistics for research variables including emotional intelligence, cultural intelligence, ethical intelligence, and performance of the public and private banks are presented in Table 2.

Table 2

The Descriptive Statistics of the Research Variables

\begin{tabular}{|c|c|c|c|c|c|c|c|c|}
\hline \multicolumn{5}{|c|}{ Public Banks $(\mathrm{N}=91)$} & \multicolumn{4}{|c|}{ Private Banks $(\mathrm{N}=16)$} \\
\hline Variable & $\begin{array}{l}\text { Emotional } \\
\text { Intelligence }\end{array}$ & $\begin{array}{c}\text { Cultural } \\
\text { Intelligence }\end{array}$ & $\begin{array}{c}\text { Ethical } \\
\text { Intelligence }\end{array}$ & Performance & $\begin{array}{l}\text { Emotional } \\
\text { Intelligence }\end{array}$ & $\begin{array}{c}\text { Cultural } \\
\text { Intelligence }\end{array}$ & $\begin{array}{c}\text { Ethical } \\
\text { Intelligence }\end{array}$ & Performance \\
\hline Mean & 3.50 & 3.23 & 3.82 & 3.64 & 3.20 & 3.55 & 3.17 & 3.81 \\
\hline $\begin{array}{l}\text { Standard } \\
\text { Deviation }\end{array}$ & 0.49 & 0.54 & 0.50 & 0.92 & 0.96 & 0.85 & 0.73 & 1.02 \\
\hline Skewness & -0.68 & -0.29 & -0.78 & -0.33 & 0.49 & 1.27 & 0.80 & 0.55 \\
\hline Stretchiness & 0.46 & 0.05 & 0.04 & -1.38 & -0.02 & 1.18 & 0.60 & -1.24 \\
\hline
\end{tabular}

Considering skewness and stretchiness of each variable and the fact that all the results were located in $[-2,2]$, it is concluded that all the variables of research statistical sample are distributed normally.

Normality testing was performed in this study and as Table 3 shows, it was found that the distribution of data was normal. 
Table 3

The Normality Test of Variables

\begin{tabular}{|c|c|c|c|c|c|c|c|c|}
\hline \multicolumn{5}{|c|}{ Public Banks } & \multicolumn{4}{|c|}{ Private Banks } \\
\hline Variable & $\begin{array}{c}\text { Emotional } \\
\text { Intelligence }\end{array}$ & $\begin{array}{c}\text { Cultural } \\
\text { Intelligence }\end{array}$ & $\begin{array}{c}\text { Ethical } \\
\text { Intelligence }\end{array}$ & Performance & $\begin{array}{l}\text { Emotional } \\
\text { Intelligence }\end{array}$ & $\begin{array}{c}\text { Cultural } \\
\text { Intelligence }\end{array}$ & $\begin{array}{c}\text { Ethical } \\
\text { Intelligence }\end{array}$ & Performance \\
\hline $\begin{array}{l}\text { Kolmogoro } \\
\text { v-Smirnov z }\end{array}$ & 1.39 & 0.83 & 1.57 & 1.35 & 0.67 & 0.71 & 0.88 & 0.64 \\
\hline $\begin{array}{c}\text { Significance } \\
\text { Level }\end{array}$ & 0.10 & 0.48 & 0.07 & 0.05 & 0.75 & 0.68 & 0.42 & 0.79 \\
\hline
\end{tabular}

As can be seen, since the significance level of each variable was not less than 0.05 , the variables were normally distributed.

\section{Research Hypotheses Testing}

As the study aimed to establish the causal relationship between the variables, regression analysis was used to test the hypotheses.

The first, second, and third hypotheses of the study were developed to evaluate the impact of emotional, cultural, and ethical intelligence (as independent variables) on improving the performance of the banks (as dependent variable) and were tested separately for the public and private banks. To test them, null and alternate hypotheses were defined as follows:

$\mathbf{H}_{\mathbf{0}}$ : The emotional, cultural, and ethical intelligence variables do not have a meaningful relationship with the improvement of the performance of the public and private banks.

$\mathbf{H}_{1}$ : The emotional, cultural, and ethical intelligence variables have a meaningful relationship with the improvement of the performance of the public and private banks.

Table 4 represents the results of regression between emotional, cultural, and ethical intelligence and performance of public and private banks.

Table 4

The Results of Regression between Emotional, Cultural, and Ethical Intelligence and Performance of Public and Private Banks

\begin{tabular}{|c|c|c|c|c|c|c|c|c|c|c|}
\hline \multirow[b]{2}{*}{ Variable } & \multicolumn{4}{|c|}{ Public Banks } & \multicolumn{6}{|c|}{ Private Banks } \\
\hline & $\mathrm{T}$ & $\begin{array}{c}\text { Significance } \\
\text { Level }\end{array}$ & $\begin{array}{l}\text { Correlation } \\
\text { Coefficient }\end{array}$ & $\begin{array}{l}\text { Durbin- } \\
\text { Watson }\end{array}$ & $\begin{array}{c}\text { Determination } \\
\text { Coefficient }\end{array}$ & $\mathrm{T}$ & $\begin{array}{c}\text { Significance } \\
\text { Level }\end{array}$ & $\begin{array}{l}\text { Correlation } \\
\text { Coefficient }\end{array}$ & $\begin{array}{l}\text { Durbin- } \\
\text { Watson }\end{array}$ & $\begin{array}{c}\text { Determination } \\
\text { Coefficient }\end{array}$ \\
\hline $\begin{array}{l}\text { Emotional } \\
\text { Intelligence }\end{array}$ & 5.34 & 0.00 & 0.49 & 1.52 & 0.24 & 6.75 & 0.00 & 0.87 & 1.03 & 0.76 \\
\hline $\begin{array}{l}\text { Cultural } \\
\text { Intelligence }\end{array}$ & 6.97 & 0.00 & 0.59 & 1.60 & 0.35 & 2.63 & 0.02 & 0.57 & 1.82 & 0.33 \\
\hline $\begin{array}{l}\text { Ethical } \\
\text { Intelligence }\end{array}$ & 4.94 & 0.00 & 0.46 & 1.66 & 0.21 & 5.08 & 0.00 & 0.80 & 1.97 & 0.64 \\
\hline
\end{tabular}

As Table 4 shows, since all the p-values were less than 0.05 in 95\% significance level, it can be concluded that the emotional, cultural, and ethical intelligence variables had a meaningful relationship with the improvement of the performance of the public and private banks.

The fourth hypothesis dealt with the determination of the degree of the importance of each dimension of the intelligence on the performance of the public and private banks. To evaluate the impact of each dimension of emotional, cultural, and ethical intelligence on improving the 
performance of the banks, multiple-regression analysis was used separately for the public and private banks.

$\mathbf{H}_{\mathbf{0}}$ : All the coefficients are zero simultaneously.

$\mathbf{H}_{1}$ : All the coefficients are not zero simultaneously.

Table 5

The Results of the Multiple Regressions between Intelligence Dimensions and Performance of the Public Banks

\begin{tabular}{lclccc}
\hline Variable Type & Symbol & Variable Name & Coefficient & T Statistic & Significance Level \\
\hline Dependent Variable & $\mathrm{Y}$ & Performance & - & - & - \\
Fixed Value & $\alpha$ & Alpha & 0.12 & 0.22 & 0.02 \\
& $\mathrm{X} 1$ & Emotional Intelligence & 0.34 & 2.62 & 0.01 \\
Independent Variable & $\mathrm{X} 2$ & Cultural Intelligence & 0.48 & 3.42 & 0.00 \\
& $\mathrm{X} 3$ & Ethical Intelligence & 0.14 & 0.88 & 0.02 \\
& & Durbin-Watson & 1.55 & - & - \\
& & B Statistic & 20.05 & - & 0.00 \\
R & & Correlation Coefficient & 0.63 & - & - \\
R-Square & & Determination Coefficient & 0.40 & - & - \\
Adjusted R-Square & & Adjusted Determination Coefficient & 0.38 & - & \\
\hline
\end{tabular}

Since all p-values in Table 5 are less than 0.05 , the hypothesis of a causal relationship between the dimensions of intelligence and the performance of the public banks was confirmed. Thus, assuming the equality of the regression coefficients and the constant value or a value of zero was rejected. In regard to the coefficients of the independent variables (emotional, cultural, and ethical intelligence), the regression equation is defined as follows:

$$
\mathrm{Y}=0.120+0.348 \times 1+0.489 \times 2+0.146 \times 3
$$

According to the coefficients of the above regression equation, the importance degree of the influence of each dimension of the intelligence to improve the performance of the public banks can be seen as numerical values.

Regarding the private banks, multiple regression test results are presented in Table 6.

Table 6

The Results of the Multiple Regressions between Intelligence Dimensions and Performance of the Private Banks

\begin{tabular}{lclccc}
\hline Variable Type & Symbol & Variable Name & Coefficient & T Statistic & Significance Level \\
\hline Dependent Variable & $\mathrm{Y}$ & Performance & - & - & - \\
Fixed Value & $\alpha$ & Alpha & -0.62 & -1.11 & 0.00 \\
& $\mathrm{X} 1$ & Emotional Intelligence & 0.85 & 3.33 & 0.00 \\
Independent Variable & $\mathrm{X} 2$ & Cultural Intelligence & 0.28 & 1.25 & 0.03 \\
& $\mathrm{X} 3$ & Ethical Intelligence & 0.44 & 1.58 & 0.04 \\
& & Durbin-Watson & 1.59 & - & - \\
& & B Statistic & 18.48 & - & 0.00 \\
R & & Correlation Coefficient & 0.63 & 0.90 & - \\
R-Square & & Determination Coefficient & 0.40 & 0.82 & - \\
Adjusted R-Square & & Adjusted Determination Coefficient & 0.38 & 0.77 & - \\
\hline
\end{tabular}


The resulted regression equation will be:

$$
\mathrm{Y}=-0.626+0.857 \times 1+0.284 \times 2+0.446 \times 3
$$

The fifth research hypothesis dealt with the meaningful and different degree of the impact of the intelligence dimensions on the performance of the public and private banks from each other. To test this hypothesis, the mean of the three dimensions of the intelligence in the public and private banks were compared. The next step was to analyse the performance of the variable between the two groups. Finally, the standardised coefficients of multiple regressions were used to compare the effects of three independent variables of emotional, cultural, and ethical intelligence on improving the performance of the public and private banks.

The results of each of the three dimensions of the intelligence in both public and private banks are presented in Table 7.

Table 7

The Results of Independent T-Test Comparing the Intelligence Dimensions between the Public and Private Banks

\begin{tabular}{|c|c|c|c|c|c|c|c|}
\hline & \multicolumn{2}{|c|}{ Public Banks } & \multicolumn{2}{|r|}{ Private Banks } & \multirow[b]{2}{*}{$\mathrm{P}$} & \multirow[b]{2}{*}{$\mathrm{DF}$} & \multirow[b]{2}{*}{$\mathrm{T}$} \\
\hline & Mean & Standard Deviation & Mean & Standard Deviation & & & \\
\hline Emotional Intelligence & 3.75 & 0.63 & 3.20 & 0.95 & 0.004 & 105 & 2.95 \\
\hline Cultural Intelligence & 3.10 & 0.72 & 2.55 & 0.85 & 0.007 & 105 & 2.67 \\
\hline Ethical Intelligence & 3.69 & 0.58 & 3.17 & 0.72 & 0.002 & 105 & 3.11 \\
\hline
\end{tabular}

As table 7 shows, the difference between the three dimensions of the intelligence in the public and private banks were meaningful at 0.05 error level. So, the dimensions of the intelligence (emotional, cultural, and ethical) in the public and private banks were different from each other.

Regarding the improvement of the performance variable in the public and private banks the results are shown in Table 8 .

Table 8

The Results of Independent T-Test to Compare the Performance Improvement of the Public and Private Banks

\begin{tabular}{ccccccccc}
\hline & \multicolumn{3}{c}{ Public Banks } & \multicolumn{3}{c}{ Private Banks } & \multirow{2}{*}{ DF } & T \\
\cline { 2 - 7 } & & Mean & Standard Deviation & Mean & Standard Deviation & P & DF \\
\cline { 2 - 8 } Ethical Intelligence & 3.48 & 0.88 & 2.81 & 1.02 & 0.007 & 105 & 2.75 \\
\hline
\end{tabular}

As the results show, at 0.05 error level it can be claimed that the performance of the public and private banks was different from each other.

To compare the effects of three independent variables of emotional, cultural, and ethical intelligence on the performance improvement of the public and private banks (the sixth research hypothesis testing), the standardised coefficients obtained from multiple regression analysis were used. 
Table 9

The Standard Coefficients Values (Beta) in Improving the Performance of the Public and Private Banks

\begin{tabular}{lccc}
\hline Variable & Emotional intelligence & Cultural intelligence & Ethical intelligence \\
\hline Public Banks & 0.25 & 0.40 & 0.09 \\
Private Banks & 0.80 & 0.23 & 0.31 \\
\hline
\end{tabular}

According to the results, emotional intelligence explained $25 \%$ of the changes of the performance improvement of the public banks while in private banks this amount was greater and equal to $80 \%$. Cultural intelligence accounted for $40 \%$ of the changes of the performance of the public banks. This effect decreased at $27 \%$ in the private banks. Finally, ethical intelligence accounted for almost $10 \%$ of the performance of the changes of the public banks while it experienced a growth in the private banks at $31 \%$. To this end, it can be concluded that the impact of emotional intelligence on improving the performance of the private banks is greater than the public banks; the impact of cultural intelligence on improving the performance of the public banks is greater than the private banks; and the impact of ethical intelligence on improving the performance of the private banks is greater than the public banks.

Demographic descriptive of the data presented that $6 \%$ of the managers of the private banks were women while the managers of the public banks were all men. The average age of the managers of the private banks was higher than the public banks. This showed that seniority and experience-orientation system was more emphasised in the public banks. Managers at the public banks had undergraduate and graduate degrees at 69\%. It experienced a slight decrease in the private banks at 63 .The findings showed that the mean of intelligence in the public bank was at its highest level. Similarly, the mean of cultural intelligence in the private banks was at its highest level. The findings of the study can be summarised as follows:

The status of emotional and cultural intelligence of the managers of the public banks of Ardabil was greater than the private banks or it was equal to the average value. However, the status of the ethical intelligence of the managers of the public banks was lower than the average value. The status of each three intelligence components of the managers of the private banks of Ardabil was more than the average value. Intelligence in the emotional, cultural, and ethical dimensions had a positive effect on improving the performance of the banks.

The impact of the cultural intelligence on the improvement of the performance of the public banks was higher than the private banks. The impact of the emotional and ethical intelligence on the improvement of the performance of the private banks was higher than the public banks.

In respect to the impact of the abovementioned intelligence dimensions on the improvement of the performance of the public and private banks, a significant difference was observed.

\section{Discussion and Conclusion}

Since the status of ethical intelligence of the managers of the public banks of Ardabil city is lower than the average value, a series of items are suggested to the managers of those banks: These items include focusing on training the staff with ethical values; trying to be a model of a strong ethical example; understanding your beliefs while sharing them with others; taking advantage of teaching moments; consider discipline as an ethical lesson; always expecting 
ethical behaviour; reacting to the effects of behaviours; strengthening and rewarding employees' ethical behaviour; prioritizing ethical principles daily; and golden rule which refers to treating others as you want to be treated and trying to use this principle as the ethical law of your organisation.

Education on the three dimensions of intelligence (emotional, cultural, and ethical) is recommended for the managers of both public and private banks. In respect to emotional intelligence, the following items need to be institutionalized: confidence reinforcement, selfawareness, understanding and recognizing all kinds of emotions, how they are formed and how to manage them, decision making in difficult and critical conditions, standing against difficulties, trying to avoid offending others, empathizing with others, caring for the needs of others, paying more attention to colleagues' emotions, trying to resolve the tensions and conflicts between colleagues, getting personal and family information from colleagues, respecting them, about cultural intelligence, enhancing understanding of different customs, respecting different tastes and preferences, respecting religious and ideological beliefs of others, respecting colleagues' dialects and languages, avoiding humiliation of colleagues, avoiding dominance and superiority; and about ethical intelligence, complying with principles and rules and adherence to them, keeping the respect of others, avoiding getting into the colleagues' personal privacy, striving for more righteousness, being confident to others, having realistic look at the mistakes, learning and getting experiences from errors and mistakes, having pioneering role in forgiving the perpetrators, fairness in reward and punishment need to be institutionalized.

The importance of the effects of cultural intelligence in the public banks needs careful attention. The importance of cultural intelligence lies in the fact that customers belong to a different race, ethnic, and culture and managers need to communicate with them in different ways.Hence, cultural intelligence can improve the performance of the managers and it can eventually result in a better performance of the organisations. In regard to the necessity of strengthening the emotional and ethical intelligence of the managers of private banks, education programs with a focus on those items is recommended.

In conclusion, educational programs on the abovementioned dimensions of the intelligence such as workshops and seminars are needed to train the managers and provide the chance for them to share their experiences with their colleagues.

\section{References}

Ang, S., Van dyne, L., \& Koh, C. (2006). Personality correlates of the four-factor model of cultural intelligence. Group Organisation\& Management, 31(1), 100-123.

Ang, S., Van Dyne, L., Koh, C., Ng, K., Templar, K., \& Tay, C. (2007). Cultural intelligence: Its measurement and effects on cultural judgment and decision making, cultural adaptation and task performance. Management \& Organization Review, 3 , $335-371$.

Ang, S.,Van Dyne, L. \& Tan, M. L. (2012). Cultural intelligence. In R.J. Sternberg \& S. B. Kaufman (Eds.), The cambridge handbook of intelligence. New York: Cambridge University Press.

Arasteh, H., \& Jahed, H. A. (2012). Observing ethics in universities and higher education institutions: An option to improve behaviour. Nesha-e elm Journal, 1(2), 21-31.

Beheshtifar, M., Esmaeli, Z., \& Nekoie Moghadam, M. (2011). Effect of moral intelligence on leadership. European Journal of Economics, Finanance and Administrative Sciences, 43, 1-7.

Borba, M. (2001). Building moral intelligence. Hoboken, NJ: Jossey-Bass. 
Borba, M. (2005). The step-by -step plan to building moral intelligence, Nurturing Kids Heart \& Souls. National Educator Award, National council of self-esteem. Jossey-Bass, 23.

Brancu, L., Munteanua, V., \& Golet, L. (2016). Understanding cultural intelligence factors among business students in Romania. Procedia-Social \& Behavioral Sciences, 221, 336-341.

Cobb, C. D., \& Mayer, J. D. (2000). Emotional intelligence: What the research says. Educational Leadership, 58, 14-18.

Crowne, K. A. (2009). The relationships among social intelligence, emotional intelligence and cultural intelligence. Organization Management Journal, 6(3), 148-163.

Earley, P. C., \& Ang, S. (2003). Cultural intelligence: An analysis of individual interactions across cultures. Palo Alto, CA: Stanford University Press.

Earley, P. C., \& Mosakowski, E. (2004). Cultural intelligence. Harvard Business Review, 82(10), 139-146.

Gardner, H. (2002). The three faces of intelligence. Daedalus, 131(1), 139-142.

Goleman, D. (1998). Working with emotional intelligence. New York: Bantam.

Haynes, N. M., \& Marans, S. (1999). The cognitive, emotional, and behavioral (CEB) framework for promoting acceptance of diversity. In J. Cohen (Eds.), Educating Minds and Hearts: Social Emotional Learning and the Passage into Adolescence (pp. 158-170). New York, NY: Teachers College Press.

Huff, K. C., Song, P., \& Gresch, E. B. (2013). Cultural intelligence, personality, and cross-cultural adjustment: A study of expatriates in Japan. International Journal of Intercultural Relations, 38, 151-157.

Kim, E. J., Yamaguchi, A., Kim, M. S., \& Miyahara, A. (2015). Effects of taking conflict personally on conflict management styles across cultures. Personality \& Individual Differences, 72, 143-149.

Li, M., Mobley, W. H., \& Kelly, A. (2016). Linking personality to cultural intelligence: An interactive effect of openness and agreeableness. Personality \& Individual Differences, 89, 105-110.

Marks, A. D. G., Horrocks, K. A., \& Schutte, N. S. (2016). Emotional intelligence mediates the relationship between insecure attachment and subjective health outcomes. Personality \& Individual Differences, 98, 188-192.

O'Donohue, W., \&Wickham, M. (2010). The role of ethical intelligence and organisational infrastructure in organisational decision-making. Proceedings of the 2010 British Academy of Management Conference, United Kingdom.

Peterson, B. (2004). Cultural intelligence: A guide to working with people from other cultures. Boston, MA: Intercultural Press.

Peter, J., P., \& Olson, J. C. (2005). Consumer Behaviour and Marketing Strategy. Boston: McGraw- Hill.

Petrides, K. V. (2011). Ability and trait emotional intelligence. In T. Chamorro-Premuzic, S. von Stumm, \& A. Furnham (Eds.), The Wiley-Black well handbook of individual differences. NewYork: Black Well Publishing.

Rahimi, G. R. (2011). The implication of moral intelligence and effectiveness in the organisation: Are they related? An International Journal of Marketing \& Technology, 1(4), 68-73.

Salovey, P., \& Mayer, D. J. (1990). Emotional intelligence. Imagination, Cognition, \& Personality, 9(3), 185-211.

Siegling, A. B., Sfeir, M., \& Smyth, H. J. (2014). Measured and self-estimated trait emotional intelligence in a UK sample of managers. Personality \& Individual Differences, 65, 59-64.

Van Dyne, L., \& Ang, S. (2006). Getting more than you expect: Global leader initiative to span structural holes and reputation effectiveness. In W. H. Mobley \& E. Weldon (Eds.), Advances in Global Leadership (101-122). New York: Elsevier/JAI Press.

Van Dyne, L., Ang, S., \& Koh, C. (2008). Development and validation of COS: The cultural intelligence scale. In S. Ana, \& L. Van Dvne (Eds.), Handbook on cultural intelligence: Theory, measurement and applications (pp. 16-38). Armonk, NY: M. E.Sharpe.

Ward, C., Wilson, J., \& Fischer, R. (2011). Assessing the Predictive Validity of Cultural Intelligence overtime. Personality \& Individual Differences, 51(2), 138-142. 